patients with severe depressions, and the expectation is that those patients with elevated 2-7 patterns will show more antidepressant responses to lithium than those with lower 2-7 patterns, our findings suggest that obsessional thinking might be as important as depression as a discriminator variable of antidepressant responses to lithium. For example, when scale 7 was used alone, our results approximated the 2-7 hit rate found by House and Martin (74\% $v 80 \%$ respectively) for the responders, suggesting that response to lithium is almost equally dependent on high scores on obsessional thinking almost as much as on depression.

These suggestions from several studies seem worthy of further investigation, given the interest being taken in attempts to find patient subgroups and potential responders prior to the weeks of treatment usually required to evaluate response or non-response to psychoactive drugs.

EDWARD F DONNELLY DENNIS L MURPHY IVAN N WALDMAN

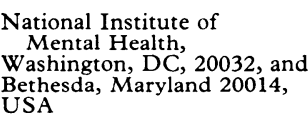

${ }^{4}$ House, K N, and Martin, R L, American fournal of Psychiatry, 1975, 132, 644.

\section{Nebulised salbutamol in life-threatening asthma}

SIR,-I was pleased to read that Dr P Bloomfield and others (31 March, p 848) were able to confirm our findings ${ }^{1}$ that nebulised salbutamol was as effective as intravenous salbutamol in the treatment of acute asthma and was free of the side effects associated with the intravenous route. However, it was disappointing to find that they used intermittent positive-pressure respiration (IPPR) from a respirator in delivering the nebulised drug and by implication advocate this form of therapy.

It is 23 years since Leslie $e t a l^{2}$ showed there to be no advantage in using IPPR in nebuliser therapy and since then there have been numerous reports confirming this finding. ${ }^{3-6}$ An editorial in Chest ${ }^{7}$ states, "Not a single well designed study has shown convincingly that a bronchodilator or any other drug delivered by this method [IPPR] is more effective than inhalation of the same aerosol delivered by a powered or hand held bulb nebuliser." Indeed, a recent study has shown that in patients with chronic bronchitis $32^{\circ}$ o less aerosol was deposited in the lungs with IPPR than during quiet breathing. ${ }^{8}$ Unfortunately, there are still many doctors who seem to think that without a mechanical respirator they cannot give their patients the full benefit of nebuliser therapy. It is unfortunate that papers such as that by Dr Bloomfield and his colleagues tend to confirm this erroneous view, and the position is not helped by the fact that the manufacturers of salbutamol refer to their product as "respirator solution." How can we get across the message that respirators for nebuliser therapy are quite unnecessary ? They are much more costly and difficult to maintain than a simple $£ 1.0$ semi-disposable nebuliser. Surely this is one area where we can move away from high technology to something simpler, less frightening, and at least as effective.

We advocate that the dose $(5-10 \mathrm{mg}$ of salbutamol) be diluted in $10 \mathrm{ml}$ of saline or water so that delivery is prolonged over a 40-minute period. This has the merit that the initial portion of the drug will be having a bronchodilator effect by the time the last portion is being inhaled. This last portion is thus able to reach parts that the initial drug was not able to reach.

J S Milledge

Northwick Park Hospital and Clinical

Research Centre

Harrow, Middx HA1 3UJ

${ }^{1}$ Lawford, P, Jones, B J M, and Milledge, J S, British Medical fournal, 1978, 1, 84 .

2 Leslie, A, Dantes, A, and Rosove, L, fournal of the American Medical Association, 1956, 160, 1125.

Goldberg, I, and Cherniack, R M, American Review of Respiratory Diseases, 1964, 91, 13.

Shenfield, G M, Evans, M E, and Paterson, J W, British fournal of Clinical Pharmacology, 1974, 1, 295.

Webber, B A, Shenfield, G M, and Paterson, J W, American Review of Respiratory Diseases, 1974, 109, 293.

6 Loren, $M$, et al, Chest, 1977, 72, 2.

7 Petty, T L, Chest, 1974, 66, 1 .

Review of Respiratory Diseases, 1977, 115, 397.

\section{New approach to treatment of recent} stroke?

SIR,-I am afraid Mr D R Gifford (2 June, p 1491) has missed the point. At no stage in my letter (12 May, $p$ 1283) did I indicate that I believed the two patients described in the manufacturer's literature had been part of Dr A K Admani's double-blind trial. What I did say, on the basis of the same literature, was that these patients "would not have qualified for the trial in the first place." Why then choose them, as examples of the alleged efficacy of the drug, rather than trial patients?

Mr Gifford's point about the date of printing of the brochure is equally irrelevant. If later criticism (10 February, p 412) of the trial is accepted by his company (and they have not attempted to answer these criticisms) why not subsequently withdraw the promotional literature, even if it is already printed?

The ethics of this particular case are now being assessed by the Association of the British Pharmaceutical Industry, and I await their comments with interest.

G D PERKIN

Charing Cross Hospital, London W6 8RF

\section{Antibiotic-induced interstitial nephritis?}

SIR,-I was interested to read the short report by Squadron Leader D Saltissi and others (5 May, p 1182) concerning antibioticinduced interstitial nephritis as the patient they describe was under my care during the first two episodes of renal failure.

The patient originally had a cystoscopy as an outpatient and returned home. His symptoms thereafter were of septicaemia rather than drug reaction, but renal biopsy showed acute interstitial nephritis and so I treated him with high doses of steroids. One month later he was admitted for elective prostatectomy but developed fever, and Escherichia coli was grown on urine culture. $\mathrm{He}$ was treated with gentamicin but the serum creatinine concentration was not measured until several days later, when it was found to be $557 \mu \mathrm{mol} / 1$ $(6.3 \mathrm{mg} / 100 \mathrm{ml})$. During this time the patient was symptomless and had a good urinary output.
Repeat biopsy showed interstitial nephritis and I considered the possibility of this being due to gentamicin. However, the histopathologist was adamant that the biopsy showed resolving interstitial nephritis by comparison with the first biopsy one month earlier and did not show convincing evidence of new interstitial nephritis. As the patient had received normal doses of gentamicin one month after suffering acute renal failure it is very likely that toxic levels of gentamicin occurred despite the implication in the report that serum concentrations were kept within recommended limits, which they were not.

I was eager to report this as the first case of gentamicin-induced interstitial nephritis but concluded that the evidence was too weak and that the alternative explanation of gentamicin nephrotoxicity in a damaged kidney could not be excluded. The third episode of renal failure is attributed to co-trimoxazole on very flimsy grounds-one wonders at the curious reluctance of the patient even to admit that he was taking it.

This is an interesting case of recurrent renal failure but the evidence does not merit the conclusion that each episode was caused by antibiotic-induced interstitial nephritis, and in the case of gentamicin the actual evidence is against it.

C T FLYNN

Iowa Lutheran Hospital,

Des Moines, Iowa 50316, USA

\section{Treatment of tinnitus}

SIR,-May I add the following practical point to your leading article on tinnitus (2 June, p 1445)? Tinnitus is a well-recognised feature of aspirin overdose, but may occur as the sole complaint at low dosages in susceptible individuals. Patients on a daily aspirin dose of only four tablets $(1.2 \mathrm{~g})$ may have troublesome tinnitus, which responds to withdrawal of the drug. In view of the widespread self-medication with aspirin-containing proprietary medicines it seems wise to exclude this ubiquitous drug as a cause of tinnitus.

$\mathrm{T}$ K DANESHMEND

University Department of Medicine,
Bristol Royal Infirmary, Bristol BS2 8HW

\section{Dialysis and transplantation in young children}

SIR,-In your recent leading article "Dialysis and transplantation in young children" (21 April, p 1033) you mentioned that the number of those treated is significantly less than the estimated requirement $(0.7 v 1.3$ per million). Similarly, "by the end of 1977 of a total of 288 children who had ever been treated in Britain only five had been aged under 5 at the start." These figures reflect the many problems encountered with the management of these patients, especially the very young ones, and the inability of inexperienced centres to cope with these problems.

The introduction of continuous ambulatory peritoneal dialysis $(\mathrm{CAPD})^{1}$ provides an alternative treatment that has many advantages and can be easily applied to children, even the very young. It is less traumatic, does not require a machine, allows more independence and an almost free diet, and promotes home dialysis.

We have recently treated with CAPD four children for periods of 3 to 11 (average 6) 